\title{
TABULAR FORM OF EULER MODIFIED METHOD
}

\author{
M. Srinivas \\ Department of Mathematics \\ Vaagdevi College of Engineering, \\ Warangal, Telangana, India
}

\begin{abstract}
There exist many single step methods to find the solution to a first order ordinary differential equation. Often time consuming and complicated. The proposed method is the alternate way of Euler modified method in the tabular form. Easy to understand and calculate
\end{abstract}

Keywords - Euler, Differential equation, Solution, Modified method.

\section{INTRODUCTION}

Several problems in science and technology can be formulated into differential equations. The analytical methods of solving differential equations are applicable only to a limited class of equations. Quite often differential equations appearing in physical problems do not belong to any of these familiar types and one is obliged to resort to numerical methods. These methods are of even greater importance when we realize that computing machines are now readily available which reduce numerical work considerably.

In the methods of Euler, Runge-Kutta, Milne, Adams-Bashforth, etc. the next point on the curve is evaluated in short steps ahead, by performing iterations until sufficient accuracy is achieved. As such, these methods are called stepby-step methods.

Euler and Runga-Kutta methods are used for computing y over a limited range of $\mathrm{x}$ - values whereas Milne and Adams methods may be applied for finding y over a wider range of $\mathrm{x}$-values.

If the conditions are prescribed at one point only (say, $x_{0}$ ), then the differential equation together with the conditions constitute an initial value problem of the nth order. If the conditions are prescribed at two or more points, then the problem is termed as boundary value problem.

The Euler method (also called as Forward Euler method) is a first-order method, which means that the local error (error per step) is proportional to the square of the step size, and the global error (error at a given time) is proportional to the step size. Here the error represents difference between the exact solution and the Euler approximation. The Euler method often serves as the basis to construct more complex methods. It is a first-order numerical procedure for solving first order ordinary differential equations (ODEs) with a given initial value. It is the most basic explicit

\author{
Md. Shafeeur Rahman \\ Department of Mathematics \\ Vaagdevi College of Engineering, \\ Warangal, Telangana, India
}

method for numerical integration of ordinary differential equations and is the simplest Runge-Kutta method.

The Euler method is more accurate if the step size is smaller

\section{Proposed Algorithm}

Step-1: Let $\frac{d y}{d x}=f(x, y)$ be the first order ordinary differential equation with the initial condition $y\left(x_{0}\right)=y_{0}$.

Step-2: Let $\mathrm{h}$ be the difference between the equally spaced data.

Step-3: Construct a table for Euler modified method with the columns

$$
\mathrm{x}, y^{1}=\frac{d y}{d x}=f(x, y) \text {, Mean and }
$$

New $\mathrm{y}=y_{0}+\mathrm{h}$ (mean) where

$\mathrm{x}=x_{0}$, mean $=$ the average of present $\mathrm{y}^{\prime}$ and starting y

Step-4: The starting value of $\mathrm{x}$ is $x_{0}$ and from the next $\mathrm{x}=x_{0}+h$

Step-5: The starting value of new y of the table only is calculated by Euler formula $y_{1}=y_{0}+h \cdot f(x, y)$.

Step-6: There is no change in the values of $\mathrm{x}$ and $y_{0}$ till the successive approximate values of new y are equal.

\section{EXPERIMENT AND RESULT}

3.1. To Find $\mathrm{y}$ at $\mathrm{x}=0.2$ of $\frac{d y}{d x}=x+y$ with the condition $\mathrm{y}(0)=1$ and $\mathrm{h}=0.1$.

Let us consider $\mathrm{f}(\mathrm{x}, \mathrm{y})=\mathrm{x}+\mathrm{y}$ and $x_{0}=0, y_{0}=1$. Constructing a table for Euler modified method by the proposed algorithm, we have 


$\begin{array}{llll}\mathbf{x} & y^{1}=\frac{d y}{d x}=x+y & \text { Mean } & \text { New } \mathrm{y}=y_{0}+\mathrm{h}(\text { mean) } \\ 0 & x_{0}+y_{0}=0+1=1 & - & \begin{array}{r}y_{1}=y_{0}+h . f(x, y) \\ =1+0.1 \mathrm{f}(0,1)\end{array} \\ & & & =1+0.1(0+1)=1.1\end{array}$

Since the last two successive values of New $\mathrm{y}$ are approximately equal, $\mathrm{y}(0.1)=1.1105$.

i.e. At $\mathrm{x}=0.1, \mathrm{y}=1.1105$

Proceeding with the next table with

$x_{0}=0.1, y_{0}=1.1105$, we have

\begin{tabular}{|c|c|c|c|}
\hline $\mathbf{x}$ & $y^{1}=\frac{d y}{d x}=x+y$ & Mean & New $y=y_{0}+\mathrm{h}$ (mean) \\
\hline \multirow[t]{3}{*}{0.1} & $0.1+1.1105$ & - & $y_{1}=y_{0}+h . f(x, y)$ \\
\hline & & & $=1.1105+0.1 \mathrm{f}(0.1,1.1105)$ \\
\hline & & & $=1.23155$ \\
\hline \multirow[t]{2}{*}{0.2} & $0.2+1.23155=1.43155$ & $\frac{1}{2}(1.43155+1.2105)$ & $1.1105+0.1(1.321)=1.2426$ \\
\hline & & $=1.321$ & \\
\hline \multirow[t]{2}{*}{0.2} & $0.2+1.2426=1.4426$ & $\frac{1}{2}(1.4426+1.2105)$ & $1.1105+0.1(1.326)=1.24315$ \\
\hline & & $=1.326$ & \\
\hline 0.2 & $0.2+1.24315=1.4431$ & $\frac{1}{2}(1.44431+1.2105)$ & $1.1105+0.1(1.32682)=1.2431$ \\
\hline
\end{tabular}

Since the last two successive values of New y are approximately equal, $\mathrm{y}(0.2)=1.2431$.

$$
\text { i.e. At } \mathrm{x}=0.2, \mathrm{y}=1.2431 \text {. }
$$

3.2. To find $\mathrm{y}(0.2)$ and $\mathrm{y}(0.4)$ of $\frac{d y}{d x}=y+e^{x}$ with $\mathrm{y}(0)=0$ and $\mathrm{h}=0.2$.

Let us consider $\mathrm{f}(\mathrm{x}, \mathrm{y})=\mathrm{y}+e^{x}$ and $x_{0}=0, y_{0}=0$.

Proceeding with the proposed algorithm for Euler modified method, From the iteration-1, $\mathrm{y}(0.2)=0.2468$.

From the iteration-2, 0.6031.
3.3 To find $\mathrm{y}(0.1)$ of $\frac{d y}{d x}=\frac{y-x}{y+x}$ with $\mathrm{y}(0)=1$ and $\mathrm{h}=0.02$.

On applying proposed algorithm,

Let $\mathrm{f}(\mathrm{x}, \mathrm{y})=\frac{y-x}{y+x}$ and $x_{0}=0, y_{0}=1$

From the iteration-1, $\mathrm{y}(0.02)=1.01961$.

From the iteration-2, $\mathrm{y}(0.04)=1.03848$

From the iteration-3, $\mathrm{y}(0.06)=1.05729$

From the iteration $-4, \mathrm{y}(0.08)=1.0755$

From the iteration-5, $\mathrm{y}(0.1)=1.0934$

\section{CONCLUSIONS}

The proposed method is the easiest way of calculating the approximate solution of first order ordinary differential equation. It is giving almost the same solution to that of standard Euler modified method.

\section{REFERENCES}

[1]. Atkinson, Kendall A. (1989). An Introduction to Numerical Analysis (2nd ed.). New York: John Wiley \& Sons. ISBN 978-0-471-50023-0.

[2]. Ascher, Uri M.; Petzold, Linda R. (1998). Computer Methods for Ordinary Differential Equations and Differential-Algebraic Equations. Philadelphia: Society for Industrial and Applied Mathematics. ISBN 978-0-89871-412-8.

[3]. Butcher, John C. (2003). Numerical Methods for Ordinary Differential Equations. New York: John Wiley \& Sons. ISBN 978-0-471-96758-3.

[4]. Hairer, Ernst; Nørsett, Syvert Paul; Wanner, Gerhard (1993). Solving ordinary differential equations I: Nonstiff problems. Berlin, New York: SpringerVerlag. ISBN 978-3-540-56670-0.

[5]. Iserles, Arieh (1996). A First Course in the Numerical Analysis of Differential Equations. Cambridge University Press. ISBN 978-0521-55655-2.

[6]. Stoer, Josef; Bulirsch, Roland (2002). Introduction to Numerical Analysis (3rd ed.). Berlin, New York: Springer-Verlag. ISBN 978-0-387-95452-3.

[7]. Lakoba, Taras I. (2012), Simple Euler method and its modifications (PDF) (Lecture notes for MATH334), University of Vermont, retrieved 29 February 2012 